\title{
O CARISMA DA RECONSTRUÇÃO: REFLEXÕES SOBRE O ATENDIMENTO DAS IRMÃS SCALABRINIANAS EM TIJUANA - MÉXICO
}

\author{
The charism of reconstruction: reflections on the service \\ of the Scalabrinian Sisters in Tijuana - Mexico
}

Igor B. Cunha*

Nathalia Vince ${ }^{* *}$

Em 2017¹, o CSEM - Centro Scalabriniano de Estudos Migratórios iniciou a pesquisa "Reconstruindo a vida na fronteira: atendimento e assistência a migrantes na fronteira Norte do México", que buscou analisar, de forma abrangente, as ações sociopastorais ${ }^{2}$ desenvolvidas no Instituto Madre Assunta (IMA) na cidade de Tijuana, pelas Irmãs Missionárias de São Carlos Borromeo - Scalabrinianas (MSCS) junto aos migrantes.

O relato a seguir recolhe reflexões sobre a atenção emergencial oferecida a mulheres e crianças migrantes pelas Irmãs MSCS após a pesquisa de campo, realizada no período de 23 de janeiro a 26 de fevereiro de 2018. Esse período de imersão etnográfica no IMA e em Tijuana envolveu um contato direto com a realidade estudada, e, de forma gradual, permitiu conversas informais e entrevistas semiestruturadas com migrantes, voluntários, funcionários do IMA e de outras instituições que prestam atendimento a migrantes em Tijuana.

Da observação sobre a rotina do atendimento a migrantes em situação de vulnerabilidade e do acompanhamento das experiências cotidianas no

\footnotetext{
Assistente de pesquisa do Centro Scalabriniano de Estudos Migratórios, CSEM. Brasília - DF, Brasil. E-mail: estudos@csem.org.br. Orcid: 0000-0002-4685-092X.

** Doutoranda no programa de pós-graduação em Estudos Comparados Sobre as Américas - ELA/ UnB, pesquisadora colaboradora do Centro Scalabriniano de Estudos Migratórios, CSEM. Brasília - DF, Brasil. E-mail: nathaliavef@gmail.com. Orcid: 0000-0002-3588-8690.

1 Para realizar este texto tomamos como base o relatório de pesquisa "Reconstruyendo la vida en la frontera. Asistencia y Atención a migrantes en la Frontera Norte de México", de autoria de: BOTEGA, Tuila; DUTRA, Delia; VINCE, Nathália; CUNHA, Igor B. Brasilia: CSEM, 2018.

2 Por sociopastorais entendemos as ações sociais desenvolvidas pelas irmãs MSCS em favor dos migrantes, especialmente os mais pobres e vulneráveis. A ação social da Igreja contempla a sensibilidade e a solidariedade para com os segmentos mais vulneráveis, o profetismo em denunciar e combater a injustiça e a espiritualidade libertadora, com o objetivo de contribuir para a formação de uma comunidade mais humana, fraterna, solidária e justa, baseada nos princípios do Evangelho e nos direitos fundamentais da pessoa humana (CNBB, 2001).
} 
IMA, infere-se a relevância de se considerar o trabalho realizado pelas irmãs MSCS como um fator que impulsiona o "refazer a vida" dessas mulheres atendidas. Nesse sentido, é instigante compreender como esse atendimento pode, de alguma forma, contribuir para a recuperação e desenvolvimento da autonomia das beneficiárias.

O Instituto Madre Assunta é a casa de acolhida para mulheres migrantes mais antiga e tradicional da região de Tijuana. Em contexto de grande migração, quer de saída, trânsito ou retorno, a chegada de pessoas em mobilidade na cidade é marcada também por um ambiente hostil ao estrangeiro - o que reflete pensamentos xenofóbicos, que são exaltados em épocas de maior intensidade, como durante as chamadas "ondas migratórias" de estrangeiros. Tais pensamentos são, muitas vezes, respaldados pelo "projeto nacionalista mestiço", um imaginário de México que não considera quem pertence a outros povos como "assimiláveis" (Gall, 2018), pertencentes ao país e, logo, merecedores de direitos. Somando-se ao machismo estrutural da sociedade mexicana (Paredes, 1971), o contexto de vulnerabilidade do público que o IMA atende é desenhado. Mulheres em situação de mobilidade estão mais vulneráveis a opressões e formas de violência que outros públicos - devido sua condição de gênero e status migratório (Woo, 2004), considerando que, historicamente, o fluxo de migração do México aos Estados Unidos é majoritariamente masculino e laboral.

Seguindo uma tendência de maior incremento de mulheres nos contextos de mobilidade (OIM, 2018), o número de migrantes femininas atendidas no local das Irmãs é muito significante. Apenas no ano de 2017, 1.275 migrantes foram recebidas no Instituto. E, nos últimos anos, a grande maioria das mulheres que chegam à "Casa" das Irmãs, como é assim chamada pelas migrantes, declararam-se solicitantes de asilo político (66\%). O segundo maior público é o de deportadas (22\%), que são canalizadas até lá por redes de organizações da sociedade civil e órgãos governamentais de assistência.

\section{Atendimento integral}

Para além de oferecer abrigo e alimentação, uma assistência social mais emergencial, o IMA procura ser um espaço onde as migrantes podem receber atendimento médico, orientação psicológica, assessoria jurídica, ter acesso aos meios de comunicação para entrar em contato com seus familiares e também terem acesso a bolsas de trabalho que são mantidas pelos convênios firmados pelo IMA com o governo local. A casa também recebe atividades de voluntários ou estagiários interessados na temática migratória. Organizações como a Save the Children fazem atividades semanais com as crianças, buscando desenvolver a expressão e comunicação por meio de atividades de desenho e pintura, além de rodas de conversa. 
As atividades desenvolvidas se adéquam à grande rotatividade de beneficiárias, tendo em vista que se trata de uma casa de passagem, com um tempo médio de permanência de 15 dias. Ainda que seja uma estadia prevista para ser de curta-duração, busca-se durante esse período oferecer um atendimento o mais amplo possível, cobrindo as mais diversas necessidades, inclusive, flexibilizando o tempo de estadia para aquelas que precisam ficar por mais tempo, como no caso de mulheres grávidas, com filhos doentes, entre outros.

Para além de um lugar de passagem, a "Casa" é um espaço para que mulheres e crianças possam se refazer, repensar o projeto migratório e replanejar o futuro. O IMA, portanto, é visto como um lugar seguro para as mulheres e crianças que chegam a Tijuana, muitas vezes, após um percurso migratório marcado por violência, fome e outras violações de direitos.

A ordem interna do IMA prevê que as migrantes "cuidem da casa", auxiliando na organização das refeições e de limpeza, por exemplo. O que, por um lado, é ressaltado como positivo por algumas migrantes, uma vez que a disciplina e ordem podem ser mecanismos importantes no sentido de ajudá-las em sua própria organização mental e interior, além de permitir espaços de troca e conversa das migrantes entre si a partir do trabalho em grupo. Mas, por outro lado, acaba limitando o acesso dessas migrantes a outras possibilidades de inserção laboral em Tijuana, ainda que temporariamente. Além disso, a colaboração no cuidado com o espaço da casa de acolhida está relacionada à concepção do assistencialismo maternalista ${ }^{3}$ - em uma realidade cujos padrões da migração feminina se entrelaçam com fatores que reforçam a divisão sexual do trabalho, a qual estabelece, convencionalmente, serviços domésticos e de cuidado às mulheres (Mora, 2007).

Além disso, o IMA oferece para além da primeira assistência, do urgente, elementos que auxiliam a reinserção da migrante no contexto mexicano ou em outras necessidades, de acordo com o projeto migratório de cada beneficiária: doações de vestimentas, oportunidades para ter acesso a empregabilidade, acompanhamento especializado para saúde mental e física e suporte legal.

$\mathrm{O}$ atendimento jurídico é principalmente buscado por quem deseja entrar com pedido de asilo político, ou por pessoas deportadas. Já na área da saúde, além dos profissionais da psicologia, o IMA recebe periodicamente a equipe médica oferecida pelo Centro Municipal de Atenção a Migrantes de Tijuana, que faz consultas de caráter urgente e os devidos encaminhamentos. Tal atividade reforça a importância das redes de cooperação para o trabalho desenvolvido

Cf. WILKINSON, Patrick. The Selfless and the Helpless: maternalism origins of the US Welfare State. Feminist Studies, v. 25, n. 3, fall 1999, p. 571-597; ABEL, Emily. Valuing Care: Turn Century Conflits between Charity Workers and Women Clients. Journal of Women's History, v. 10, n. 3, autumn 1998, p. 32-52. 
pelas irmãs, especialmente no contexto de carência nos serviços básicos de atenção à população que Tijuana enfrenta - só há um hospital público na cidade.

Um grande suporte ao trabalho das Irmãs no local é a chamada Coalición Pro Defensa del Migrante, uma coalizão, ou rede, dos albergues que têm como público alvo a população em situação de mobilidade e que possuem uma experiência já consolidada ao longo dos anos na prática da acolhida. Esta rede se apoia principalmente no direcionamento de migrantes recémchegados no Módulo de atenção El Chaparral, principal guarita de chegada de deportados em Tijuana, aos albergues pertencentes à Coalición. Um escritório foi cedido à rede pelo governo federal mexicano no local para o acolhimento imediato de deportados, que os aloca nos albergues conveniados à rede por meio de um veículo próprio. Há também projetos recebidos do governo para a rede visando a população repatriada, como a disponibilização de passagens de ônibus a quem deseja regressar a seu lugar de origem.

Graças a esta articulação, eventos de sensibilização são promovidos e projetos podem ser melhor aproveitados, atingindo um número maior de pessoas. A participação nessa rede permite também o remanejamento de beneficiários, como por exemplo, quando o perfil da atendida puder causar danos à integridade psicofísica das demais, como pessoas em situação de drogadição que, no caso, são encaminhadas a centros de reabilitação; ou quando não são consideradas migrantes, sendo direcionadas a outras casas de acolhida específicas. Eventualmente, as trabalhadoras de serviço social do IMA também se encarregam de direcionar beneficiárias a outros locais, assegurando o direito à assistência a quem precisa - sendo esta uma das premissas do trabalho das Irmãs no local - nunca deixar alguém que precise de abrigo na rua.

Na casa, busca-se conceder uma atenção personalizada, que é possível a partir do levantamento de dados sobre as mulheres e crianças que ali chegam. Ao serem recebidas, além de receberem um kit de higiene básica e algo para alimentar-se, são encaminhadas à assistente social para uma entrevista, a qual busca levantar informações pessoais e sobre a trajetória migratória: motivação da migração, como fez o trajeto até Tijuana, quais as perspectivas futuras, etc. Todas essas informações permitem aprimorar a atenção integral sem deixar de considerar as especificidades que cada pessoa traz.

Esse tipo de atuação é mais factível em momentos de menor demanda, como no inverno, porém se torna mais complexo e desafiador, como mencionam as próprias Irmãs, nos períodos de "ondas migratórias", situações cada vez mais recorrentes, como no caso da recepção de migrantes haitianos em 2016 e das caravanas migrantes a partir do ano de 2018. Em tempos de "crises", com número de beneficiários aumentado, a rotina de atendimento precisa ser flexibilizada e alterada. Em vez da entrevista completa, ao chegarem, 
os avisos gerais sobre regras e rotinas da casa são dados a um grupo, para dar agilidade ao processo. Tais situações emergenciais impõem a necessidade de "reinventar" o atendimento, demandando mais donativos e estruturas para acomodação - como colchões e camas extra, maior disponibilidade de tempo das Irmãs e voluntários visando que a casa comporte o maior número possível de pessoas, entre outros.

A importância do atendimento imediato no contexto de Tijuana contribuiu para conformar o processo de acolhida do IMA e definir a temporalidade da estadia. Apesar da opção por fazer um trabalho de curto prazo, de alguma forma, implicar em algumas limitações como citado anteriormente, foi percebido que em alguns casos há a tentativa de acompanhamento informal das migrantes após deixarem o albergue. Ainda assim, a rotatividade de beneficiárias traz dificuldades para viabilizar o processo de acompanhamento prolongado.

\section{A espiritualidade como fator de reconstrução}

Também em entrevistas, notou-se que depois de processos traumáticos, muitas pessoas que estão em situação de mobilidade sentem a necessidade de "agarrar-se em algo". A fé, segundo a psicóloga voluntária da casa, serve como ferramenta no processo de recuperação dos momentos de risco à vida humana que o trajeto migratório até Tijuana muitas vezes implica. A figura das Irmãs religiosas remete à espiritualidade cristã e fortalece o sentimento de estar próximo a uma estrutura de apoio, com a qual as pessoas não se sentem sozinhas.

Ainda, para mulheres que migram diante de muito medo aos riscos do mundo patriarcal, onde o feminino é visto como inferior e a hierarquização se dá a favor dos indivíduos do gênero masculino (Facio, Fria, 2005), receber ajuda de mulheres nas quais confiam que não the farão mal é crucial para a recuperação psicológica - assim se encaixam as Irmãs scalabrinianas.

Nesse sentido, um dos elementos utilizados no atendimento às migrantes e que se insere na rotina da casa é a atenção espiritual. Ainda que de forma facultativa, e em respeito àquelas que não professam crença religiosa, as orações proferidas antes das refeições são um exemplo de comunhão que integra todos da casa em um momento de agradecimento. Nas palavras de uma estagiária do IMA, as atividades espirituais auxiliam as migrantes a não desistirem; reforçam a ideia, das que creem e se usufruem das atividades, de que Deus ajudará seu futuro.

O Instituto Madre Assunta não faz distinção de religião ao receber as migrantes. Tampouco são mandatárias as atividades de espiritualidade a quem passa por lá. No entanto, constata-se que a maioria participa das orações e momentos de reflexão espiritual, sendo católicas ou não. Novamente, a imagem 
das religiosas que administram o albergue atrai o sentimento de segurança, paz e comunhão, guiados pelo exemplo da dedicação que as próprias Irmãs dão em seu incansável trabalho em defesa e acolhimento aos migrantes.

A espiritualidade também é um fator de reconstrução para as próprias Irmãs, trabalhadores e voluntários da casa, aqueles que atuam diretamente na recepção de migrantes e têm contato com suas histórias de sofrimento e dor e, obviamente, não ficam alheios a elas. Para eles, a espiritualidade é também uma forma de aliviar e ressignificar as emoções e de fortalecimento interior para continuar exercendo suas funções. O sistema da fé, ao dar valor à vida, reforça a compreensão de que continuar acolhendo é o que "se deve" fazer. A diretora do IMA, Ir. Adélia Contini, ressalta que os princípios religiosos, do carisma scalabriniano em prol dos migrantes, estão presentes nas atividades desempenhadas na casa. As ações sociopastorais no âmbito migratório acabam sendo, desta forma, uma manifestação de acolhida incondicional de cada pessoa humana, independentemente de sua identidade cultural, social ou religiosa (Anthony, 2012).

\section{Reconstruindo vidas na fronteira}

O atendimento a migrantes em situação de vulnerabilidade é um dos grandes desafios às instituições que acolhem essa população em regiões de fronteira, especialmente em Tijuana, um dos maiores corredores migratórios do mundo.

No caso do IMA, com suas potencialidades e limitações, esse atendimento é possível a partir da união de diversos fatores. O primeiro é a experiência das Irmãs Scalabrinianas com o atendimento direto, ou seja, por conta do seu carisma e da experiência de toda uma vida trabalhando com esta população, as Irmãs são capazes de dar respostas rápidas às necessidades emergenciais das migrantes, sabem como resolver problemas e como acolher as mulheres que chegam ali. O olhar humano das Irmãs consegue identificar as necessidades das mulheres e crianças migrantes e encaminhá-las para um atendimento específico. Segundo uma psicóloga voluntária, é geralmente uma Irmã a primeira pessoa a perceber que a migrante precisa passar pelo seu atendimento.

O segundo fator é o carisma scalabriniano, que faz com que as Irmãs estejam mais conectadas à vida dessas migrantes. A psicóloga da casa também acredita que as Irmãs MSCS representam uma figura materna para as crianças e para as migrantes. Não raro, elas são chamadas de mãe ou avó pelas beneficiárias do albergue. Cria-se assim um laço de confiança importante para a recuperação psicofísica e a reconstrução da confiança, necessária para prosseguir ou reconstruir o projeto migratório. A representação daquelas que são consagradas à vida religiosa thes traz uma ideia de segurança e paz. 
O terceiro fator é a confiança no Instituto Madre Assunta, pelo trabalho realizado ao longo dos mais de vinte anos de atuação. A confiança na instituição e na figura das Irmãs Scalabrinianas também promove uma boa reputação gerando a possibilidade de que projetos sociais e financiamentos possam ser captados pelo IMA e gerem ainda mais perspectivas de atendimento às migrantes.

Um desafio em todo atendimento direto é o de abarcar as diversidades e lograr a reinserção social e laboral de todos os perfis de sujeitos atendidos. A entrevista realizada quando da entrada das migrantes no IMA permite escutar as pessoas atendidas, desenhar um quadro de suas necessidades, bem como oferecer respostas adequadas diante de cada um dos casos. O Instituto Madre Assunta se encontra em posição estratégica, tanto geograficamente, quanto institucionalmente, por possuir experiência e história no atendimento a migrantes e por estar inserido em uma rede de casas de acolhida, para potencializar as atividades de assistência a mulheres e crianças migrantes. Ao continuar investindo tempo e dedicação nesse serviço de escuta personalizada se incrementa a capacidade de reinvenção de seus procedimentos e, em última instância, se avança no sentido da promoção de um "atendimento integral", mesmo em situações desafiadoras em que se demanda uma resposta humana e solidária a quem precisa, com respeito ao diferente.

\section{Bibliografia}

ANTHONY, Francis-Vincent sdb. Desenraizamento e acolhida: fundamentos para uma pastoral migratória. REMHU, Revista Interdisciplinar da Mobilidade Humana, v. 20 n. 38, p. 195-212, 2012.

CNBB, Setor Pastoral Social. O que é Pastoral Social? São Paulo: Loyola, 2001.

FACIO, Alda; FRIES, Lorena. Feminismo, género y patriarcado. Academia. Revista sobre enseñanza del derecho de Buenos Aires, n. 6, p. 259-294, 2005.

GALL, Olivia. Racismos y xenofobias mexicanos frente a los migrantes: 1910-2018. REMHU, Revista Interdisciplinar da Mobilidade Humana, v. 26, n. 53, p. 115134, 2018.

MARINUCCl, Roberto. Feminization of migration? REMHU, Revista Interdisciplinar da Mobilidade Humana, v. 15, n. 29, p. 5-22, 2007.

MORA, Luis. Globalización, migración internacional y división sexual del trabajo. Una mirada desde el género y los derechos reproductivos. Notas de población, n. 85, Santiago de Chile, CEPAL, p. 115-144, 2007.

PAREDES, Américo. The United States, Mexico, and "Machismo". Journal of the Folklore Institute, v. 8, n. 1, p. 17-37, 1971.

WOO, Ofelia Morales. Abuso y violência a las mujeres migrantes. In: FERNANDEZ, Teresa de Juan (coord.). Violencia contra la mujer en México. Primeira edição. Comisión Nacional de los Derechos Hmanos, 2004. 